Página inicial: 128 - Página Final: 144

Tipo de artículo: Investigación.

\title{
El exterminio del Movimiento Cívico del Oriente de Antioquia.
}

\author{
The Extermination of the Civic Movement in the Eastern Region in Antioquia.
}

Por: Carlos Hernando Olaya Rodríguez ${ }^{1}$

Recibido: junio de 2016 Revisado: noviembre de 2016 Aceptado: diciembre de 2016

\section{Resumen.}

Durante los años cincuenta y sesenta del siglo veinte se produjo en Colombia una gran migración de población rural hacia las ciudades, a causa de la atroz violencia que vivió el país en esa época, y por la atracción de trabajadores agrarios hacia el sector industrial productor de bienes básicos, que se expandió notoriamente en aquel momento. Esto provocó el aumento de la demanda de electricidad, por lo cual, las empresas de servicios públicos de Medellín, Bogotá y Cali diseñaron grandes proyectos de generación hidroeléctrica.

Palabras claves. Hidroeléctricas, conflictos sociales, conflicto armado, despojo, territorio, movimiento cívico, oriente antioqueño.

\begin{abstract}
.
During the 1950's and the 1960's, a large rural migration to the cities took place in Colombia, as a result of the heinous acts of violence, which the country experienced in that time, and by the attraction of agricultural workers toward the industrial sector, which is the producer of commodities and which was spread notoriously in that moment. This led to the increase in the demand of electricity, for such a reason, the utility companies of Medellin, Bogota, and Cali, designed great projects of hydroelectric generation.
\end{abstract}

Key words. Hydroelectric Power Stations, Social Conflicts, Armed Conflict, Plundering, Territory, and Civic Movement Oriente Antioqueño.

\footnotetext{
${ }^{1}$ Historiador de la Universidad de Antioquia, investigador del grupo Kavilando, Medellín, (Colombia). Contacto: carlos-h-olaya-r@hotmail.com
} 
Ante las limitaciones para la financiación estatal de la infraestructura requerida para suministrar energía al centro del país, el gobierno autorizó a las Empresas Públicas de Medellín para que emprendieran la construcción de la hidroeléctrica de Guatapé. Luego, con el propósito de llevar electricidad a la costa Atlántica, se fortaleció la empresa Interconexión Eléctrica S.A. (ISA) con la inclusión de las principales generadoras regionales como socias del Estado en el impulso del sector eléctrico nacional. Simultáneamente se gestionó con organismos de crédito internacional el dinero que hacía falta para la construcción de estas mega-obras; de ahí que con el crédito externo y aún en proceso de construcción de la central de Guatapé, ISA emprendió la construcción en el municipio de San Carlos de una hidroeléctrica con la mayor capacidad instalada del país. A esta le siguieron Jaguas, Calderas y Tafetanes, ubicadas en esta misma área. Paralelamente se autorizó a las Empresas Públicas de Medellín emprender la construcción de la central de Playas, ubicada entre las represas de Guatapé, Jaguas y San Carlos. Vale decir que, la central San Carlos genera 1.240MW, Guatapé 560 MW, Jaguas 170 MW, Playas 200 MW, Calderas 7.4 MW y Tafetanes 1.9 MW. (Olaya Rodríguez, 2012)

En la ejecución de estos proyectos se dispuso toda la capacidad de endeudamiento del país con los organismos de crédito internacionales, de modo que entre 1970 y 1987, el Banco Mundial hizo préstamos a Colombia para este tipo de proyectos por un valor cercano a los US $\$ 1.900$ millones, y el Banco Interamericano de Desarrollo contribuyó con una suma similar”.

En el estudio realizado por Ochoa, Smith Quintero, \& Villegas Botero, (2002) titulado: El Sector Eléctrico Colombiano. Orígenes, evolución y retos. Un siglo de desarrollo. [1882-1999], se indica que la búsqueda afanosa de recursos para acometer las obras de infraestructura eléctrica llevó a contratar los fondos más costosos disponibles, no obstante contar la garantía de la nación. En consecuencia, durante la década de los años ochenta "el sector eléctrico fue objeto de operaciones masivas de financiamiento por parte del Gobierno, bajo modalidades como la utilización de excedentes de las empresas industriales y comerciales del Estado para pagar el servicio de la deuda, partidas directas del presupuesto nacional, créditos contratados directamente por el ministerio de Hacienda o garantías otorgadas por la nación", de manera que “entre 1978 y 1988, las transferencias del gobierno para asumir la deuda fueron de US\$1.100 millones.

Los promotores de la expansión del sector eléctrico en Antioquia decidieron la ubicación de las represas en el oriente, dadas las óptimas condiciones que brindaban las pendientes del terreno y la abundancia de aguas, además de que, para instalar a bajo costo el kilovatio hora, consideraron que podrían adquirir las tierras de estos lugares a bajos precios; a la vez que subestimaron los impactos sobre la población local.

La construcción de la hidroeléctrica de Guatapé acarreó la inundación de una extensa area agrícola al igual que el casco urbano de El Peñol, ante lo cual, las Empresas Públicas de Medellín firmaron con los concejos municipales de El Peñol y Guatapé un Contrato Maestro, elevado este a escritura pública No 175 de abril 12 de 1969, mediante el cual EPM se comprometió a reparar los daños ocasionados con las obras e indemnizar a los afectados.

Además, entre otras cláusulas, quedó establecido que dos años antes de la inundación debían estar las casas del nuevo Peñol construidas y habitables. Sin embargo, para el primer semestre 
de 1978, fecha de la inundación definitiva, los pobladores denunciaron que ni siquiera las vías públicas se habían construido.

Es de precisar que, la represa de El Peñol tiene una extensión de $62 \mathrm{~km} 2$ y una capacidad de almacenamiento de 1.200 millones de metros cúbicos de agua. El llenado total se calculó entre dos y dos años y medio. Datos tomados del informe presentado el día de cierre de las compuertas de la represa. (El Colombiano, 1978)

Por su parte, según datos publicados en el libro: El Ave Fénix", referido a ese periodo de la historia de El Peñol, en la fase de adquisición de tierras fue asesinado el médico Demetrio Galeano Jácome, el 19 de octubre de 1965, a manos, presuntamente, de un carabinero de la policía que prestaba sus servicios en las oficinas de EPM, ubicadas en una hacienda del sector. Según el texto citado, don Demetrio era propietario de una gran extensión de tierras ubicadas en la rivera del rio Nare, por lo que su muerte fue ordenada al negarse a venderlas para ser inundadas. (Rivera Galeano, 2014).

Los pobladores de El Peñol que vivieron la construcción de la represa efectuada entre los años 1970 y 1978 comentan que la experiencia les costó sangre y fuego, pues, cada que se movilizaban pidiendo soluciones a las problemáticas creadas con la inundación de las tierras, llegaba el ejército a reprimirlos. No obstante, los afectados persistían en los intentos de detener las obras, mediante bloqueos en lugares estratégicos, para impedir el tránsito de la maquinaria pesada, exigiendo que primero fuera solucionada la afectación de la comunidad. (Cardona González, 2007)
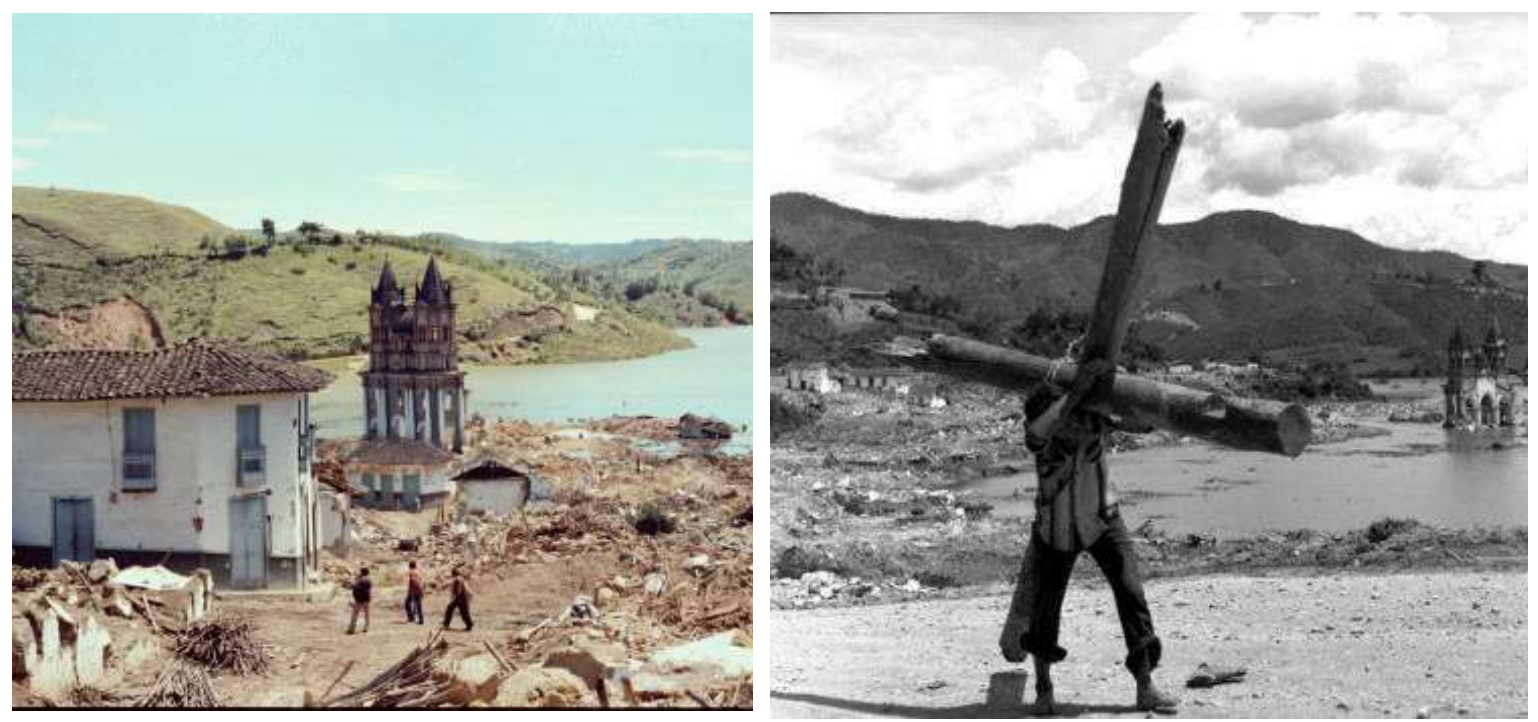

Foto: proceso de Llenado del Embalse. Fuente: Archivo histórico Alcaldía de Guatapé

A pesar de todo, el 25 de mayo de 1978, literalmente les echaron el agua encima a quienes todavía no habían desocupado las viviendas en su totalidad. Al respecto, en una entrevista a uno de los sacerdotes que presenció la inundación, este afirmó: "Una vez que se cerraron las compuertas 
eso se volvió fue una evacuación, para que no pasara una tragedia. Porque ¿quién ataja el agua? Nadie. (Cardona González, 2007)

La inconformidad de los pobladores de El Peñol y Guatapé debido a la imposición de esta mega-obra por encima del querer de toda una comunidad y las maneras propias de habitar el territorio por parte de los campesinos, propicio el surgimiento de un fuerte movimiento cívico, que canalizó la voz de los afectados.

Lo que sucedía en El Peñol y Guatapé puso sobre aviso a los habitantes de San Carlos, al saber que allí el gobierno nacional, a través de ISA, emprendería la construcción de la hidroeléctrica de mayor capacidad instalada del país. Por eso también se conformó, en esta localidad, un fuerte movimiento cívico, a través del cual se presentaron reclamaciones, acompañadas de grandes movilizaciones, para exigir indemnizaciones, compensaciones, reubicaciones y planes de mitigación por los perjuicios causados, al igual que participación en los espacios donde se tomaban las determinaciones sobre la destinación de los recursos públicos, los cuales eran manejados de manera fraudulenta por los políticos de turno.

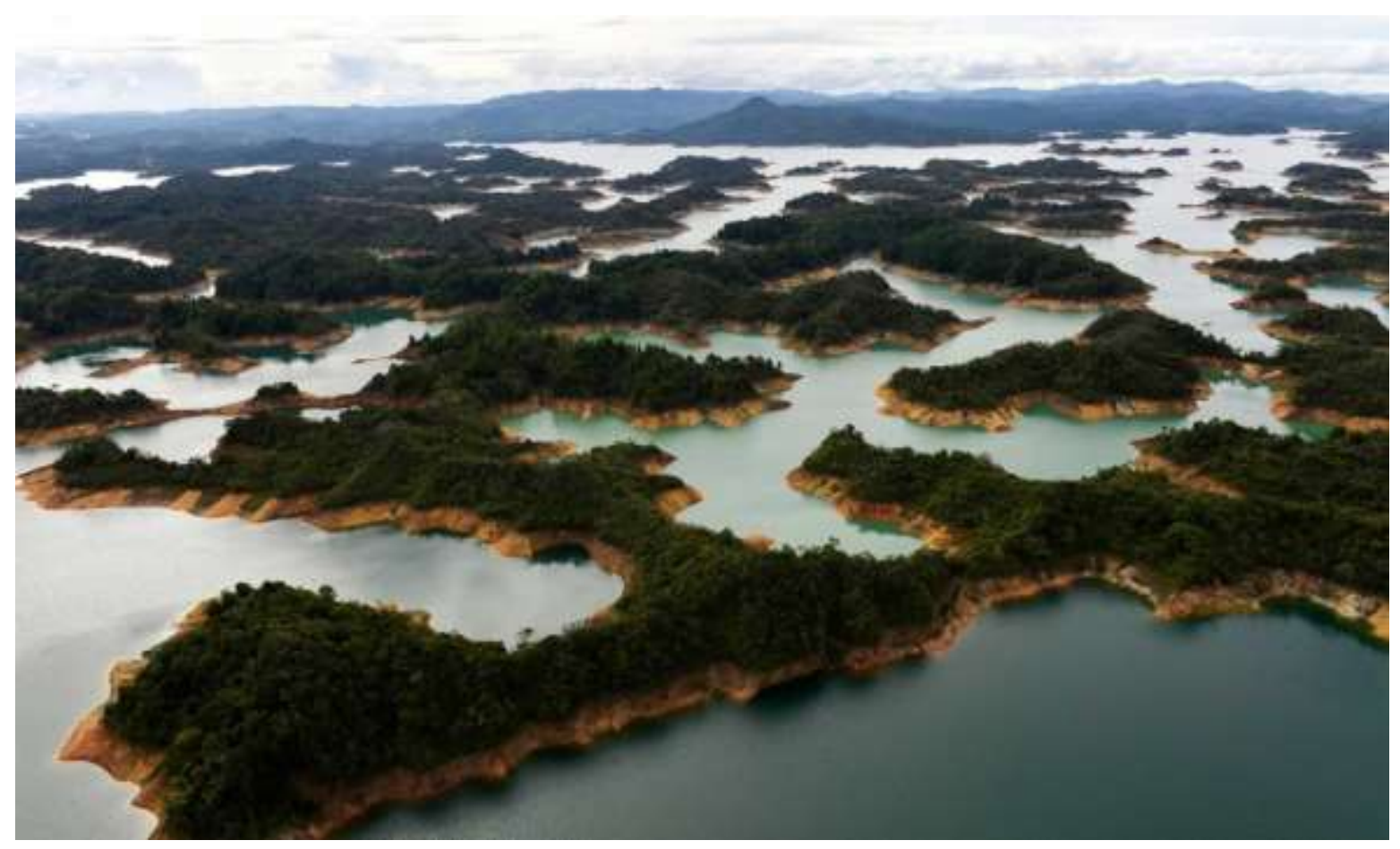

Foto: panorámica Embalse Guatapé.

Además de las anteriores, otra de las razones para que se extendiera el movimiento cívico por todo el oriente de Antioquia fue que los gobernantes del departamento crearon a la electrificadora de Antioquia S.A, pretendiendo intervenir en el negocio de la electrificación, pese a que los municipios venían impulsando los circuitos eléctricos, los cuales tuvieron que sumarse a la nueva empresa por orden de la gobernación, sin que se hubiera tenido en cuenta a la 
ciudadanía, que se había entusiasmado con la gestión subregional del recurso hídrico. Al final la electrificadora se dedicó a la comercialización de energía, que compraba en bloque a las Empresas Públicas de Medellín, para revenderla en los municipios ubicados por fuera del área metropolitana del Valle de Aburra. Pero, debido a las limitaciones de esta empresa, los cortes en el servicio y la precariedad en el suministro se hicieron frecuentes, lo que acrecentó el malestar de los pobladores de la región con el ente intermediario.

La inconformidad de la ciudadanía por el manejo de la política energética salió a flote en noviembre de 1981, cuando la electrificadora de Antioquia notificó el alza gradual de las tarifas, hasta un 35\%. El hecho de que la empresa buscara la rentabilidad del negocio en el corto plazo, elevando las tarifas de manera abrupta, provocó que la comunidad rechazara de manera rotunda a la empresa intermediaria.

La nivelación tarifaria fue programada para un tiempo máximo de seis meses y, en cumplimiento de esa disposición, en enero de 1982 empezaron a llegar las facturas con un recargo del 9\%, lo que creó un malestar general que provocó que en los distintos municipios del oriente de Antioquia se convocaran asambleas populares, en las cuales se adoptó la determinación de no pagar las cuentas. Inmediatamente se constituyeran juntas cívicas encargadas de llevar la vocería de los usuarios.

Frente a la suspensión masiva del pago de las facturas, los directivos de la electrificadora ordenaron el corte del servicio. La población reacciono para impedir los cortes o restablecer las conexiones, por lo cual, varios integrantes del movimiento cívico fueron detenidos por la policía. Al final, en muchos lugares la gente optó por desmontar los medidores y conectarse directamente "hasta que no se resolviera el conflicto".

Debido a que en cada localidad se presentaba una problemática similar, se convoco a un encuentro regional en el municipio de Rionegro, al cual acudieron delegados de cada junta constituida, además de representantes de organizaciones sindicales y campesinas. (Ruiz, 1983) Allí se acordó realizar reuniones quincenales, en cada uno de los municipios comprometidos. Cada quince días se efectuaron encuentros regionales en los que se informaba del curso del movimiento y se definían las tareas a desarrollar, hasta la siguiente reunión. Entre tanto la electrificadora de Antioquia emprendió una intensa campaña publicitaria en contra del movimiento, mientras que en varios municipios se prohibieron las asambleas populares. No obstante, la ciudadanía se vinculaba cada vez más a la protesta.

El 26 de junio de 1982, transcurridos cinco meses de conflicto, en una asamblea realizada en Marinilla, se constituyó oficialmente la Coordinadora Regional de Juntas Cívicas Pro-Defensa de los Usuarios de la Energía, integrada por representantes de cada una de las juntas municipales asistentes al evento. A este organismo se le encomendó la tarea de llevar la representación ante el gobierno, con la exigencia de liquidar la electrificadora y tramitar la suspensión de los cortes de energía, así como la prestación del servicio por parte de EPM. Para presionar la negociación y fortalecer el movimiento, se organizaron foros y marchas regionales a las que asistían delegaciones de todos los municipios. 


\section{Acciones realizadas.}

Frente a la intransigencia del gobierno para atender las reclamaciones se realizó:

El primer paro cívico regional: el 9 de septiembre de 1982, con una duración de 48 horas. Rionegro, Marinilla, La Unión, El Retiro, El Santuario, San Vicente, Guarne, La Ceja, El Carmen de Viboral, El Peñol, Cocorná, Granada y San Carlos fueron los municipios que se vincularon a la protesta, mediante la cual se exigió respuesta a una serie de exigencias recogido en el "Pliego de peticiones de la comunidad del oriente antioqueño al gobierno nacional, al gobierno departamental, a las Empresa Públicas de Medellín, al Instituto Colombiano de Energía Eléctrica a Interconexión eléctrica S.A. y a Electrificadora de Antioquia", presentado en el mes de agosto de 1982. Los puntos centrales exigidos con la protesta eran: Prestación del servicio de energía por parte de las Empresas Públicas de Medellín, de modo que la Electrificadora de Antioquia quedaría descartada como ente intermediario. Además, se solicitaron tarifas preferenciales, en razón de ser una región productora de energía y en compensación por la afectación acarreada con las hidroeléctricas, así como la congelación de las tarifas y el desmonte del sistema Upac aplicado al cobro de este servicio. También se demandó la eliminación de las multas por el no pago de las facturas y un plazo de doce meses para su cancelación. La jornada de protesta también demandó el cumplimiento del contrato maestro suscrito por las Empresas Públicas de Medellín con los municipios de El Peñol y Guatapé.

El gobernador del momento, Álvaro Villegas Moreno, calificó el paro cívico como un "movimiento subversivo programado por doce anarquistas", a pesar de que se había reunido con los representantes de la Coordinadora Cívica el lunes 6 y miércoles 8 de septiembre, días previos al inicio del cese de actividades, para discutir las peticiones planteadas. (El Colombiano, 1982)

En medio de la movilización fueron detenidos quinientos diez manifestantes, según denunciaron voceros de la Coordinadora Cívica, razón por la cual se determinó la continuidad del paro, de forma indefinida, hasta tanto no fueran puestas en libertad todas las personas capturadas y las peticiones fueran atendidas. En el comunicado donde se anunció la continuidad del paro, la Coordinadora rechazó el calificativo de "subversivo", dado al movimiento por parte del gobernador (El Mundo, 1982). En la tarde del domingo 12 de septiembre de 1982 se llegó a un preacuerdo, declarando una prórroga de 15 días, tiempo en el cual se debía llegar a un arreglo definitivo.

Los puntos pactados para el levantamiento del Paro Cívico fueron: No pago del servicio de energía en los quince días de la tregua declarada, ni corte del servicio durante ese tiempo. Libertad para todos los detenidos. Retiro de la fuerza pública desplegada en los municipios. No represalias contra los promotores del paro cívico. Establecimiento de los términos para la disolución de la electrificadora de Antioquia y renegociación de las deudas.

El levantamiento del paro cívico fue declarado en una asamblea popular realizada al mediodía del domingo 12 de septiembre de 1982, en el parque central de Marinilla, a la que asistieron delegados de todos los municipios comprometidos. En el evento se tomó la determinación que, si para el mes siguiente no se cumplían los acuerdos, se convocaría una nueva jornada de protesta de mayor envergadura.

\begin{tabular}{l|l|l|l|l|l|l} 
AGO.USB & Medellín - Colombia & Vol. 17 No. 1 & PP 1 - 323 & enero - junio & 2017 & ISSN: 16578031
\end{tabular} 
Segundo paro cívico regional: El principal obstáculo para la solución de este conflicto se debió a que el gobernador se oponía a la liquidación de la electrificadora, aduciendo que la supresión del ente intermediario era imposible, argumentando que "ello generaría un grave traumatismo que perjudicaría a toda la comunidad". (El Mundo, 1982) De fondo, la negativa del gobernador obedeció a que tenía claros intereses económicos y políticos en torno al manejo de la nómina y recursos de esta empresa, aun cuando una comisión técnica había recomendado la liquidación de dicha entidad "por inviable". Además, como la decisión de la prestación del servicio por parte de EPM la debía tomar la Junta directiva, en cabeza de Álvaro Uribe Vélez, temporalmente alcalde de Medellín, quien se oponía radicalmente a que se aceptaran las peticiones del movimiento, tal determinación parecía imposible de tomar; por lo tanto, la declaratoria del nuevo paro se hizo inevitable.

Ante el incumplimiento de los acuerdos a los que se llegó con el movimiento anterior y la negativa del gobierno para el dialogo, se decidió convocar al segundo paro cívico, esta vez con carácter indefinido. El paro fue programado a partir de las doce de la noche del lunes 11 de octubre de 1982.

En solidaridad con la región del Oriente, el Concejo municipal de Santa Bárbara se declaró en sesión permanente; y los municipios de Andes, Urrao, Bolívar, Amalfi y Cisneros anunciaron también su respaldo a la protesta. Igualmente, en Riosucio (Caldas), Villavicencio y el Putumayo se presentaron sendos paros cívicos en los que, en medio de fuertes protestas, se produjeron varios muertos y heridos a manos de la fuerza pública.

Las asociaciones comunales del barrio San Pío de Itagüí bloquearon el transporte; en Medellín, se realizó una movilización que marchó desde la plazuela de Zea hasta la Gobernación. Por su parte, los estudiantes de las universidades de Antioquia y la Nacional también realizaron acciones en solidaridad con las comunidades del Oriente, en tanto la autopista Medellín-Bogotá y las vías rurales de la región, fueron regadas con tachuelas para impedir el tráfico vehicular. (El Mundo, 1982)

El jueves 14 de octubre de 1982, en las horas de la tarde, dos delegados de la Coordinadora sostuvieron una conversación con el gobernador, quien se comprometió a retirar la fuerza pública de las calles, mientras se convocaban asambleas populares para analizar un posible preacuerdo, sobre la base de los temas planteados en la entrevista con el gobernador. Al día siguiente, se realizó una reunión entre el gobernador, los miembros de la Coordinadora Regional y el delegado del Presidente de la República, Joaquín Vallejo Arbeláez, donde se acordó el retiro de la Electrificadora en un plazo máximo de cuatro meses, y la prestación del servicio por parte de EPM, según cuatro alternativas planteadas por el movimiento cívico.

Era claro que, en cualquiera de las alternativas que se asumiera, las tarifas serían las mismas del Área Metropolitana, no sólo en cuanto al consumo, sino en lo referido a matrículas, multas, sistemas de cobro, recargos y reconexiones. (El Mundo, 1982) Estas fueron: Fusión o integración de la Electrificadora de Antioquia con las Empresas Públicas de Medellín. Prestación del servicio

\begin{tabular}{l|l|l|l|l|l|l} 
AGO.USB & Medellín - Colombia & Vol. 17 No. 1 & PP 1 - 323 & enero - junio & 2017 & ISSN: 16578031
\end{tabular} 
por parte de EE.PP.MM con la constitución de una empresa de energía para el sector, distinto al área metropolitana, pero en la cual, EE.PP.MM asumiría la dirección financiera, técnica y administrativa. Prestación del servicio por parte de EE.PP.MM, a través de su organización administrativa. Contratación entre los municipios del Oriente que así lo deseen y las EE. PP MM, del servicio de energía, en las modalidades de venta en bloque o servicio directo, de acuerdo con la preferencia de cada municipio.

Se pactó, así mismo, la eliminación del cobro del recargo rural y el cumplimiento de la ley 56 de 1981. Respecto al pago de las cuentas atrasadas, se determinó que en cada cuenta mensual se adicionaría una décima parte de la deuda, condonando multas, sanciones y recargos. Para los reclamos sobre posibles errores en la liquidación de las cuentas, se acordó que estos se resolverían dentro de los tres meses siguientes, descontando de las cuentas los excesos de pago que se presentaran.

Sobre los detenidos se dispuso que de inmediato fueran puestos en libertad, que no se expidieran multas por las excarcelaciones y que no hubiera ninguna represalia contra los participantes en el paro. Adicionalmente, se determinó el nombramiento de un veedor para el convenio suscrito, de una lista de cinco candidatos, debidamente calificados, presentada por la junta coordinadora de los movimientos cívicos al gobernador.

Con la firma del acuerdo se decidió el levantamiento del paro, aunque los delegados de la Coordinadora manifestaron que los resultados de la negociación serían presentados en las asambleas populares para su ratificación. Finalmente, el paro fue levantado en medio de la satisfacción por la liquidación de la Electrificadora de Antioquia. Aun así, el gobierno departamental solo realizó el cambio de nombre, adoptando el de Empresa Antioqueña de Energía (EADE), pero continuó la deficiencia en la prestación del servicio, lo mismo que la diferencia tarifaria respecto al área metropolitana del Valle de Aburrá, lo que provocaría un nuevo paro ć́vico.

Veinticinco años después las tarifas de energía fueron niveladas con las del área metropolitana del Valle de Aburrá, y la prestación del servicio fue asumido, al mismo tiempo, por EPM, puesto que EADE desapareció como ente intermediario. Esto se produjo por el traslado a la región del oriente de muchas de las industrias del Valle de Aburrá, proporcionando, de ese modo, bajas tarifas para su operación. El cambio de operador se hizo con mucha facilidad para el gremio de los industriales; en cambio, para los usuarios comunes y corrientes, demandó grandes penalidades. De paso, la nivelación tarifaria fue utilizada por EPM para obtener nuevas ganancias corporativas, dado que ello significó aumentar las tarifas en Medellín y el área metropolitana.

Tercer paro cívico regional: Siendo las doce de la noche del domingo 19 de febrero de 1984 se dio inicio al tercer paro cívico del oriente de Antioquia, al que se sumaron varios municipios del suroeste del departamento. El movimiento tenía la misma finalidad del realizado en el año 1982: rechazar las altas tarifas de la energía eléctrica y exigir tarifas preferenciales, en razón a ser una región productora de energía. Fue antecedido por una manifestación realizada en el parque central del municipio de Rionegro. Estuvo signado por hechos violentos en los que resultaron muertos tres dirigentes del Frente Democrático, en el municipio de Fredonia, ubicado en el suroeste del departamento, mientras que en Medellín e Itagüí hubo parálisis del transporte 
público y fueron apedreados y quemados varios vehículos. En San Carlos un estudiante fue asesinado por la policía y varios pobladores resultaron heridos. El comercio del oriente antioqueño cerró sus puertas y tanto la autopista Medellín-Bogotá como las demás vías de la región fueron bloqueadas (El Mundo, 1984).

El tercer paro cívico del oriente se prolongó durante toda una semana en tanto que en el municipio de San Carlos se extendió una semana más, presionando para que además de las reivindicaciones regionales fueran atendidas las peticiones de un pliego local, dada la grave afectación de este municipio con la construcción de las hidroeléctricas. Pero los gobernantes departamentales y nacionales, representantes de los intereses de los grandes grupos económicos, desoyeron las peticiones de los pobladores; dejaron pasar los días sin atender las justas reclamaciones, desgastando la protesta, pues no estaban dispuestos a gobernar en función de las necesidades y aspiraciones populares.

Al concluir el tercer paro cívico, se dio la voz de alerta por las graves amenazas sobre los promotores del movimiento (El Mundo, 1984). El peligro que se cernía sobre los líderes cívicos se agravaba con los señalamiento efectuados por el periódico El Colombiano, que nombraba a los dirigentes de la protesta con los calificativos de: "extremistas, subversivos, anarquistas, revoltosos y agitadores profesionales" (El Mundo, 1984); (El Colombiano, 1984); (El Colombiano, 1984) \& (El Colombiano, 1984), poniéndolos en alto riesgo frente a los recién creados grupos paramilitares que profesaban un peligroso credo antisubversivo, según el cual la protesta popular se considera como parte de la supuesta estrategia de la guerrilla para derrocar al Estado.

El movimiento cívico del oriente de Antioquia, tanto en lo regional como lo local, denotó una gran capacidad organizativa y de movilización, pero la respuesta fue el asesinato sistemático de todos aquellos que encausaron y organizaron el descontento popular contra la prevalencia de los intereses de los grupos empresariales y del Estado burocrático en la región. La criminalización de la protesta llevó a que el movimiento cívico se paralizara en medio de la ola de crímenes que cubrió al país en la década de los años ochenta. 


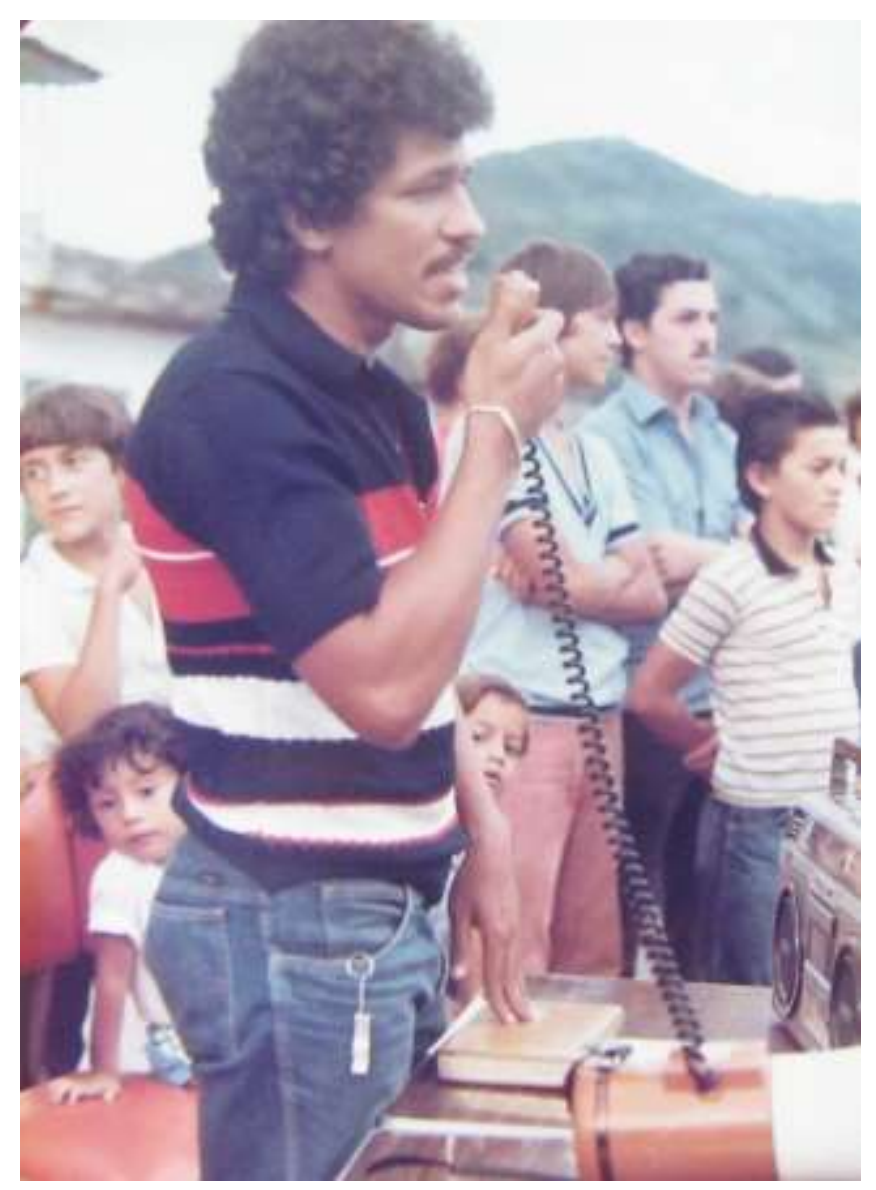

Foto: Julián Darío Conrado David. (Olaya Rodriguez, 2014)

Los dirigentes del movimiento cívico del oriente de Antioquia empezaron a ser asesinados el 23 de octubre de 1983, fecha en la cual fue acribillado por un sicario el médico Julián Conrado David, en el municipio de San Carlos.

Julián era médico, graduado en la Facultad de Medicina de la Universidad de Cartagena se dirigió a la ciudad de Medellín a realizar el internado en el Hospital San Vicente de Paul. Un año después, a solicitud del director de este hospital se fue hacia el municipio de San Carlos, Antioquia, a realizar el año rural. Durante su estadía allí se integró a los círculos que impulsaban el movimiento cívico; agrupación de ciudadanos que reclamaban por la afectación con la construcción de las hidroeléctricas. Luego de su asesinato, la comunidad rápidamente se dio cuenta de que la autoría intelectual del homicidio provenía del grupo de ultraderecha que controlaba la alcaldía, y que el inspector de policía fue el organizador del acto criminal. (Olaya Rodríguez, 2014) La muerte de Julián Conrado fue promovida entonces, por políticos locales que se confabularon con el grupo paramilitar denominado muerte a secuestradores MAS, surgido en esa época en la región del Magdalena Medio, área cercana a San Carlos.

A este crimen le siguieron los asesinatos de Jaime Giraldo e Iván Castaño, masacrados el domingo 19 de agosto de 1984, en el parque central de este mismo municipio. A partir de ahí 
seguirá una ola de persecución y asesinato sistemático de los líderes del Movimiento Cívico a manos de grupos de sicarios provenientes de la región del Magdalena Medio, apoyados por el ejército, la policía y algunos pobladores locales, financiados económicamente por personas adineradas, en especial por aquellos que venían haciendo fortuna en el negocio del narcotráfico.

A mediados del año 1985 los escuadrones de la muerte recrudecieron sus acciones contra los habitantes de San Carlos, a tal punto que en tan solo algunos meses acribillaron a treinta pobladores, hecho denunciado ante las autoridades por los líderes del movimiento cívico, denuncia que no fue atendida. (Olaya Rodríguez, Denuncia pùblica presentada por la junta cívica de San Carlos , 1986).

En enero del año 1986 se presentaron graves amenazas de muerte contra varios dirigentes cívicos que tampoco fueron atendidas por las autoridades. Como resultado, el viernes 28 de febrero de 1986, fue asesinado Gabriel Velásquez Urrego. Luego, en la tarde del jueves 20 de marzo fue baleado en la ciudad de Medellín, William Genaro Tamayo Giraldo, después de haber tenido que salir de San Carlos ante el peligro que se cernía sobre los dirigentes cívicos del municipio. Esta serie de crímenes provocaron que cientos de pobladores de San Carlos abandonaran la localidad por temor a ser víctima de los paramilitares.

Posteriormente, el sábado 28 de noviembre de 1987 fue asesinado Froilán Arango Echavarría, concejal de la UP en el municipio de San Rafael y miembro del Comité Cívico del Oriente, organización popular que impulsaba la defensa de los derechos de los campesinos y mineros damnificados por la construcción de las hidroeléctricas de Playas y Jaguas, ubicada entre los municipios de San Carlos, San Rafael y San Roque.

La siguiente víctima del movimiento cívico fue el odontólogo y profesor universitario, Jorge Alberto Morales Cardona, asesinado el lunes 11 de abril de 1988 al frente de la Facultad de Odontología de la Universidad de Antioquia, lugar donde laboraba. El crimen fue reivindicado por el grupo "Medellín Urbano Extrema Derecha", según indicó el periódico El Colombiano. (El Colombiano, 1988)

Jorge Morales estuvo vinculado al movimiento cívico de San Carlos y fue elegido para el Concejo de este municipio, en representación de la Unión cívica municipal UCM, en dos períodos consecutivos; el primero, en las elecciones del 11 de marzo de 1984, y, el segundo, en las de marzo de 1986, motivo por el cual se había granjeando la animadversión de los jefes políticos de San Carlos que se oponían radicalmente a este movimiento popular. Había recibido amenazas de muerte de parte de los grupos paramilitares, por tanto, había decidido suspender las visitas al municipio.

La Unión Cívica Municipal UCM fue un grupo constituido por líderes del movimiento cívico de San Carlos, quienes se propusieron llevar representantes propios al concejo municipal, buscando tener mayores posibilidades de incidencia en los destinos de la localidad. La participación en elecciones inicio en el año 1980, logrando posicionar hasta tres de once escaños, en dos periodos consecutivos. Para 1986, como consecuencia de la persecución y muerte a que 
fueron sometidos los miembros del movimiento cívico, esta nueva agrupación desapareció del escenario político.

Luego, en junio de 1988, fue asesinado Luis Felipe Noreña. El crimen sucedió al interior de un establecimiento comercial de la ciudad de Cali, capital del Valle del Cauca, hasta donde llegaron los sicarios que perseguían a los miembros del movimiento cívico para matarlos. Cuatro meses después, el viernes 7 de octubre de 1988, fue acribillado Alberto Giraldo Castaño, el crimen ocurrió en la heladería Villamil ubicada al frente de la Universidad de Antioquia. La acción fue ejecutada por dos sujetos que huyeron en una motocicleta de alto cilindraje. (El Mundo, 1988) \& (El Mundo, 1988).

Alberto Giraldo se desempeñó como miembro activo de la Junta Cívica de San Carlos y al momento de su muerte cursaba el último semestre de Sociología. Su deceso se produjo en medio de la celebración de los 185 años de la Universidad de Antioquia. Por el hecho, las directivas dispusieron el cierre de la Universidad desde la mañana del sábado 8 hasta el lunes 10 de octubre (El Colombiano, 1988). Según expresaron familiares y allegados, el crimen fue perpetrado por individuos oriundos del municipio de San Carlos, quienes hacían parte de los "escuadrones de la muerte" que asolaron a este y otros municipios del oriente de Antioquia. (Entrevista a pobladores de San Carlos integrantes del movimiento cívico. Medellín. [s.e]. Abril de 2011)

Tres meses después fue asesinado Antonio Martínez Moreno, quien había sido miembro activo de la Coordinadora de Movimientos Cívicos del Oriente Antioqueño. Al momento de su muerte era concejal de la Unión Patriótica, en el municipio de El Carmen de Viboral, y presidente del sindicato de trabajadores de la empresa Textiles Rionegro, filial de Coltejer. El crimen ocurrió en la madrugada del jueves 5 de enero de 1989, después de que el bus en que se transportaba junto a varios trabajadores de la empresa Textiles Rionegro, fuera retenido por doce individuos fuertemente armados que se movilizaban en varios vehículos. (El Colombiano, 1989) \& (El Mundo, 1989).

Posteriormente, el viernes 27 de octubre de 1989, fue asesinado Gabriel Jaime Santamaría, en el recinto de la Asamblea Departamental de Antioquia (El Colombiano, 1989, Pp. 1-2) (El Colombiano, 1989, Pp. 10-11). Gabriel Jaime Santamaría había estado en la dirección del movimiento cívico del oriente de Antioquia. Al momento de su muerte, era diputado y segundo vicepresidente de la Asamblea departamental, en representación de la Unión Patriótica. También era coordinador regional de ese movimiento político. Su muerte se produjo en medio de la oleada de crímenes que se sucedieron en aquel período, tanto contra los dirigentes del Movimiento Cívico de Oriente como de la Unión Patriótica.

De la misma manera, el sábado 30 de diciembre de 1989, fue asesinado el reconocido dirigente cívico y candidato a la alcaldía de Marinilla, Ramón Emilio Arcila, junto al estudiante de ingeniería eléctrica de la Universidad Nacional, sede Medellín, Saturnino López Zuluaga. (El Colombiano, 1990)

En rechazo a este doble crimen, las organizaciones populares de Marinilla declararon un paro cívico de 72 horas. El movimiento de protesta fue acogido por los establecimientos comerciales, de modo que el pueblo se vio paralizado desde el 31 de diciembre hasta el primero de enero siguiente a las 11 de la mañana, hora en que se llevó a cabo el funeral. 
Ante el inminente peligro que representaba el haber estado vinculado al movimiento cívico o participar en organizaciones políticas por fuera de los partidos tradicionales, los sobrevivientes se vieron obligados a abandonar la región y buscar refugio en distintas partes, dentro y fuera del país, ubicándose en lugares donde encontraron condiciones favorables para la sobrevivencia. No obstante, varios de los integrantes del movimiento, aun habiendo hecho una pausa en su participación en actividades cívicas y comunitarias, fueron víctima de asesinato, persecución y estigmatización por parte de quienes se habían empeñado en el exterminio del grupo emergido de las entrañas del pueblo oriental, que se había atrevido a disputarles los espacios de representación a los gamonales.

Con el desplazamiento de los líderes del movimiento cívico, los municipios quedaron enteramente a disposición de los partidos tradicionales, que adecuaron sus prácticas a las nuevas condiciones creadas con la introducción de la elección popular de alcaldes y gobernadores, iniciada en el año 1988 y los cambios constitucionales efectuados en el año 1991. Valiéndose de los nuevos mecanismos legales los mismos políticos que promovieron el exterminio del movimiento cívico continuaron al frente de las instituciones de la región, mientras que quienes se atrevieron a disputarles los espacios en concejos y alcaldías, se vieron enfrentados a maquinaciones y mañas para sacarlos del camino; porque, pese a la criminalización del movimiento cívico, algunos líderes, junto a nuevos grupos de pobladores, tanto urbanos como rurales, empezaron a impulsar propuestas de cambio, buscando modificar las prácticas, métodos y estilos de gobierno mantenidas por los partidos tradicionales después de la expedición de la constitución.

La posibilidad de intervención en la administración pública fue habilitada por la Constitución de 1991, que facultó a las comunidades organizadas para que participaran en la planeación de la vida municipal. Con esa base algunos de los líderes del movimiento cívico se dispusieron a impulsar propuestas, según las nuevas disposiciones legislativas. Entre ellos se encontraba Ernesto Ríos Arias, un reconocido dirigente del movimiento cívico del oriente antioqueño en la década anterior, quien para el año 1994 impulsaba un nuevo movimiento que lo llevó al Concejo del municipio de la Unión. Sin embargo, debido a intereses mezquinos de políticos locales y regionales ligados a este municipio, sus familiares y allegados atribuyen la causa de su muerte a manos de sicarios dentro de su oficina, ubicada en pleno centro de Medellín. (El Colombiano, 1995)

Igual sucedió en el municipio de San Carlos donde un grupo de pobladores decidieron buscar participación en las instancias de administración local, con la convicción de que, tanto a la Alcaldía como al Concejo municipal, debían llegar personas calificadas y de reconocimiento social por su compromiso con la comunidad. Con esa finalidad se constituyó un movimiento comunitario denominado "Unidos por San Carlos", al cual se vincularon algunos dirigentes del movimiento cívico que se habían visto forzadas a salir del municipio a causa de la violencia anterior, pero, estaban empezando a retornar, gracias a que, para ese momento, se respiraba cierto aire de tranquilidad en la región.

Este movimiento se extendió a otras localidades bajo el nombre de "Oriente Unido", retomando las propuestas del movimiento cívico de la década pasada. A través de esta organización se impulsaron diferentes eventos regionales, aunque, rápidamente fue objeto de 
señalamientos, de "estar promovida por la guerrilla", lo que significaba poner a sus integrantes nuevamente en la mira de los paramilitares. Aun así, el movimiento mantuvo la coordinación entre los diferentes municipios de la región, durante varios años.

El movimiento "Unidos por San Carlos" presentó candidato propio a la alcaldía para las elecciones de octubre de 1994, además de varias listas para el concejo municipal. Con ello se buscaba posicionar el mayor número posible de personas que se pusieran al frente de los proyectos que requería el municipio. Al final, lograron varios escaños. Sin embargo, en medio del reagrupamiento de los sectores políticos locales y regionales, reaparecieron los problemas en cuanto a la participación política de carácter popular, a la vez que se presentaba una fuerte presencia de grupos guerrilleros en las áreas rurales.

En medio de esta situación fue asesinado el alcalde recién elegido en San Carlos. En su reemplazo el gobernador del departamento, Álvaro Uribe Vélez quiso designar a un militar, pero las organizaciones comunitarias rechazaron esta pretensión. Finalmente, la gobernación accedió al nombramiento del alcalde propuesto por las asociaciones comunitarias. Así, con el respaldo de la nueva administración, las organizaciones sociales emprendieron diversos proyectos, diseñados para enfrentar las profundas dificultades económicas en que había quedado sumido este municipio, después de la culminación de la construcción de las hidroeléctricas, y las secuelas de la violencia de la década anterior (Botero Londoño \& Uribe Tirado, 1998).

\section{Conclusiones.}

El nuevo auge alcanzado por el movimiento cívico de San Carlos en aquel momento ha sido caracterizado como crucial para sacar adelante al municipio, después de las calamidades padecidas en las décadas anteriores. Pero los promotores del paramilitarismo, en su estrategia de ocupar y controlar este territorio, estigmatizaron a la población sancarlitana, señalándola de tener vínculos con los grupos guerrilleros. Así, crearon las condiciones para destruir aquella expresión organizada, autónoma, de las comunidades, a través de masacres, desapariciones forzadas y asesinatos sistemáticos contra la población civil inerme, ocurridos consecutivamente durante casi una década.

Los paramilitares se instalaron de forma permanente en el corregimiento el Jordán, en el casco urbano de San Carlos, en San Rafal y varios municipios del oriente de Antioquia, donde establecieron sus bases de operaciones durante varios años, a la vista de todos, con la complacencia de las fuerzas del ejército y policía.

Entre los líderes del movimiento cívico de San Carlos asesinados en medio de la arremetida de los grupos paramilitares iniciada a finales de la década de los años noventa, están Mariano Bedoya, Jaime Botero, Rocío Giraldo, Libardo Duque y Víctor Velásquez, masacrados junto a otros seis pobladores, el 24 de octubre de 1998, cuando el grupo paramilitar conocido como "Bloque Metro", liderado por alias Doble Cero y los hermanos Muñoz apodados Jota y Castañeda, oriundos del corregimiento el Jordán, irrumpieron en el casco urbano de San Carlos y sacaron a las víctimas de sus viviendas para asesinarlas cobardemente.

A Libardo Duque y Víctor Velásquez les cortaron las cabezas con una motosierra para ser llevadas como trofeo, demostrando la crueldad y sevicia como actuó esta horda de asesinos. 
El 24 de octubre de 1998, cuando irrumpieron los paramilitares en el casco urbano de San Carlos, estos le recordaban a la gente que en esa fecha habían asesinado al médico Julián Conrado.

Posterior a esta masacre y hasta el año 2007, tanto la población de San Carlos como los municipios del oriente de Antioquia, en general, padecieron una catástrofe humanitaria sin precedentes. En ese período se produjo una danza de guerra aciaga, en la cual los paramilitares masacraban indiscriminadamente a los habitantes de los municipios, mientras que las guerrillas atacaban los cascos urbanos de todas las localidades de la región, sostenían fuertes enfrentamientos con el ejército en las áreas rurales y mataban a los pobladores que consideraban informantes o auxiliadores de los paramilitares. En ese momento, la arremetida paramilitar contra la población civil se desarrolló en proporción geométrica a la operatividad insurgente contra las fuerzas del Estado.

Por causa del conflicto armado, un gran porcentaje de habitantes de las diversas poblaciones del oriente de Antioquia se vieron forzados a huir hacia distintas areas, en especial hacia las grandes ciudades, donde tuvieron que enfrentar grandes penalidades para la sobrevivencia. Pasada la confrontación armada en la cual la población civil inerme resulto hondamente afectada, muchos han retornado a sus parcelas y lugares de trabajo, apoyados con planes del gobierno para el retorno y el restablecimiento de los derechos conculcados.

Entre las medidas adoptadas para la reparación a las víctimas de la violencia está la ley 1448 de 2011(ley de víctimas y restitución de tierras). Sin embargo, el grupo empresarial Argos pretende ahora, a través de la empresa Celsia, represar al río Samaná Norte para la hidroeléctricas Porvenir II que generará 352 MW, afectando a los municipios de San Carlos, San Luis, Puerto Nare y Caracolí, así como a las poblaciones ribereñas de los ríos Nare y Magdalena. Además, los administradores de la empresa ISAGEN, recién adquirida por inversores extranjeros, pretenden construir otra central llamada Palaguas, también sobre el rio Samaná Norte, la cual, de construirse, afectaría de manera grave y definitiva a la población de pescadores que ancestralmente han vivido de los recursos que proporciona este rio. Por su parte, la gobernación de Antioquia, a través del Instituto para el desarrollo de Antioquia IDEA, se propone impulsar la construcción de microcentrales en todo el departamento, más de sesenta de ellas en el oriente de Antioquia, proyectos que afectaran de nuevo a las comunidades que han retornado al territorio.

Con la imposición de estos nuevos proyectos hidroeléctricos, se ponen en entredicho las medidas establecidas a través de la ley 1448 de 2011 y recursos legales adicionales para la reparación y restitución de tierras a las víctimas de la violencia que recién acaba de pasar, al igual que los avances en términos de restablecimiento de derechos. Este es el panorama que se presenta hoy día, lo cual denota una nueva conflictividad social, dado que las comunidades se han venido organizando y movilizando para oponerse al despojo que significan estos proyectos. Los campesinos que se verán afectados afirman que, de no atenderse de manera adecuada este conflicto, pueden presentarse hechos lamentables, similares o peores a los ocurridos anteriormente. 
Por lo tanto, se requiere del apoyo de la sociedad colombiana en general, al igual que de la comunidad internacional, para que se tomen todas las medidas que impidan que esto vuelva a ocurrir.

\section{Bibliografía.}

Botero Londoño, L., \& Uribe Tirado, L. (1998). San Carlos: La costica dulce de Oriente. La participacion politica de las organizaciones sociales en la gestión pública. Medellín: INER.

Cardona González, P. A. (2007). Tejiendo memoria del viejo Peñol. Recuperacion Historica. Trabajo presentado para optar al titulo de peridista Facultada de comunicaciones (págs. 42-46). Medellin: Universidad de Antioquia.

El Colombiano. (25 de mayo de 1978). Inoforme cierre de las compuertas Represa de Guatape. El Colombiano, pág. p. 1 y 15 a.

El Colombiano. (10 de septiembre de 1982). "movimiento subversivo programado por doce anarquistas",. El Colombiano, pág. p. 1 y 11 a.

El Colombiano. (22 de febrero de 1984). "extremistas, subversivos, anarquistas, revoltosos y agitadores profesionales”, . El Colombiano, pág. p. 5b y 6b.

El Colombiano. (23 de febrero de 1984). "extremistas, subversivos, anarquistas, revoltosos y agitadores profesionales”, . El Colombiano, pág. p. $10 \mathrm{~b}$.

El Colombiano. (25 de febrero de 1984). "extremistas, subversivos, anarquistas, revoltosos y agitadores profesionales”, . El Colombiano, pág. p. 2a.

El Colombiano. (9 de octubre de 1988). Asesintato de Alberto Giraldo y otros lìderes. El Colombiano, pág. P. 10d.

El Colombiano. (12 de abril de 1988). Medellin urbano extrema derecha. El Colombiano, pág. p. 1.

El Colombiano. (28 de octubre de 1989). Asesinado Gabriel Jaime Santamaría. El Colombiano, pág. p. 1 y 2.

El Colombiano. (29 de octubre de 1989). Asesinado Gabriel Jaime Santamaría. El Colombiano, pág. p. 10.

El Colombiano. (6 de enero de 1989). Asesinato del lider sindical Antonio Martínez Moreno. El Colombiano, pág. p. 8A.

El Colombiano. (3 de enero de 1990). Asesinado Ramón Emilio Arcila. El Colombiano, pág. p. 1 y 2.

El Colombiano. (6 de enero de 1990). Asesinado Ramón Emilio Arcila. El Colombiano, pág. p. 10 y 11.

El Colombiano. (4 de mayo de 1995). Asesinato de Ernesto Ríos Arias. El Colombiano, pág. p.3a.

El Mundo. (13 de octubre de 1982). Movimiento civico oriente Antioqueño. El mundo, págs. seccion 1, p. 1.

El Mundo. (11 de septiembre de 1982). Paro civico del oriente Antioqueño. El Mundo, págs. p.1 y seccion 2,p. 1.

El Mundo. (12 de octubre de 1982). Paro civico oriente Antioqueño. El Mundo, págs. seccion 2, p. 1. 
El Mundo. (16 de octubre de 1982). Paro Civico oriente antioqueño. ElMundo, págs. seccion 1, p.10.

El Mundo. (4 de marzo de 1984). Tercer paro civico. El Mundo, pág. p. 10.

El Mundo. (21 de febrero de 1984). Tercer Paro civico oriente antioqueño. El Mundo, págs. p. 1,8 y 9 .

El Mundo. (8 de octubre de 1988). Asesinato de Alberto Giraldo Castaño. ElMundo, pág. p. 13 a.

El Mundo. (9 de octubre de 1988). Asesintato de Luis Felipe Noreña y otros lìderes. El Mundo, pág. p. 1 y $12 \mathrm{a}$.

El Mundo. (6 de enero de 1989). Asesinado lider sindical. El Mundo, pág. 8A.

Insuasty Rodriguez, A. (13 de Febrero de 2011). Soberanía popular en nuestros territorios. En defensa de la vida, el territorio, el agua, la cultura. Kavilando, 3(1), 4-6. Obtenido de http://kavilando.org/revista/index.php/kavilando/article/view/141/125

Insuasty Rodriguez, A., \& Grisales González, D. (2016). Minería, Conflictos Territoriales Y Derechos De Las Victimas En Colombia. Medellin: Kavilando.

Insuasty Rodriguez, A., \& Villa Gòmes, J. D. (2016). Entre la participación y la resistencia: reconstrucción del tejido social desde abajo, más allá de la lógica de reparación estatal. El Agora USB, 453-478.

Insuasty Rodriguez, A., Balbin Alvarez, J. W., Fernandez Quintero, M., \& Cadavid Acevedo, P. (2009). Victimas, violencia y despojo. Medellìn: Kavilando.

Ochoa, F., Smith Quintero, R., \& Villegas Botero, L. J. (2002). El sector ele $\square$ ctrico colombiano : or $\square$ genes, evolucio $\square$ n y retos o un siglo de desarrollo, 1882-1999. Bogota $\square$, D.C. : Interconexio $\square$ n Ele $\square$ ctrica S.A.

Olaya Rodríguez, C. (1 de diciembre de 1986). Denuncia pùblica presentada por la junta cívica de San Carlos . Archivo personal. San Carlos, Antioquia, Colombia: Archivo personal.

Olaya Rodríguez, C. (2012). Nunca mas contra nadie. Medellín: Cuervo Editores.

Olaya Rodriguez, C. (15 de febrero de 2014). Julián Darío Conrado David. Un ejemplo de dignidad. Asesinado en Octubre de 1983. Obtenido de Kavilando: http:/ / kavilando.org/index.php/2013-10-13-19-52-10/organizaciones-sociales-ypopulares /2526-julian-dario-conrado-david-un-ejemplo-de-dignidad-asesinado-enoctubre-de-1983

Olaya Rodriguez, C. (2015). Conflictos socio-ambientalesen el Oriente Antioqueño. Kavilando, 15-21.

Rivera Galeano, H. L. (2014). El Ave Fenix. Relatos sobre la historia de un pueblo que emerge de las cenizas. El Peñol: una historia para contar. Medellin: Maspapelito S.A.S.

Ruiz, C. (1983). El oriente antioqueño: un pueblo en lucha. Marinilla: ENS. 